\title{
Pd-pincer complexes containing six-membered rings that are more active allylation catalysts than five-membered ring analogues
}

\author{
Dan E. Wise, ${ }^{\mathrm{a}}$ Natalie E. Pridmore, ${ }^{\mathrm{a}}$ Paul G. Pringle ${ }^{\mathrm{a}}$

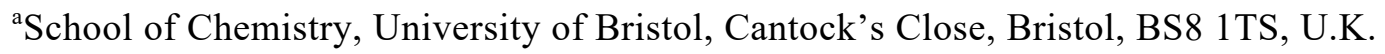

\begin{abstract}
A series of symmetric and non-symmetric $P C P$-pincer complexes have been prepared and an evaluation of their activity in catalytic allylic alkylation carried out. The X-ray crystallography and NMR spectroscopy data suggest that metallacycles containing one (or two) 6-membered rings are inherently more rigid than initially anticipated. The observed catalyst activity is found to increase as the metallacycle size increases from 5 to 6 .
\end{abstract}

\section{Introduction}

Since the pioneering work on cyclometalated phosphine pincer complexes by Shaw et al. and amine pincer complexes by van Koten et al. in the 1970 s, chemists have exploited the tunability of pincer complexes to develop many thousands of variants. ${ }^{1,2}$ The rich chemistry of pincer complexes is attributed to the many points of derivatisation present, such as the donor atoms and substituents, backbone structure, metal centre, and ancillary ligands. The applications of transition metal pincer complexes in catalysis have been extensively reviewed. ${ }^{3-7}$

Most pincer complexes are derived from $C_{2 \mathrm{v}}$ symmetric ligands which give rise to complexes with two fused 5-membered metallacycles (i.e. 5,5-metallacycles). ${ }^{3}$ Less well studied are pincer complexes with fused 6-membered metallacycles (i.e. 6,6-metallacycles). ${ }^{8-10}$ Pincer complexes containing 6-membered metallacycles have a larger P-M-P bite angle and would be anticipated to be more conformationally flexible. In some cases, they have been shown to have superior catalytic properties compared to 5,5-metallacyclic systems. ${ }^{11-14}$ Very few pincer complexes with non-symmetric 5,6-metallacycles have been reported ${ }^{9,15}$ and the only P-containing, non-symmetric 5,6-metallacycles are bis-phosphite (A) and phosphine-phosphite Pd complexes, reported by Eberhard et al. ${ }^{11,16}$ In the 2018 review by Crabtree et al., ${ }^{3}$ it was noted that there were very few examples of pincer ligands with non-symmetric metallacycles. The high thermal stability that pincer complexes have compared to many other organometallic complexes, is attractive for their applications in biological and catalytic contexts. ${ }^{17}$ The following examples demonstrate the enhanced reactivity that may be gained when using larger, non-symmetric pincer metallacycles. 
a) Previously studied metallacycles
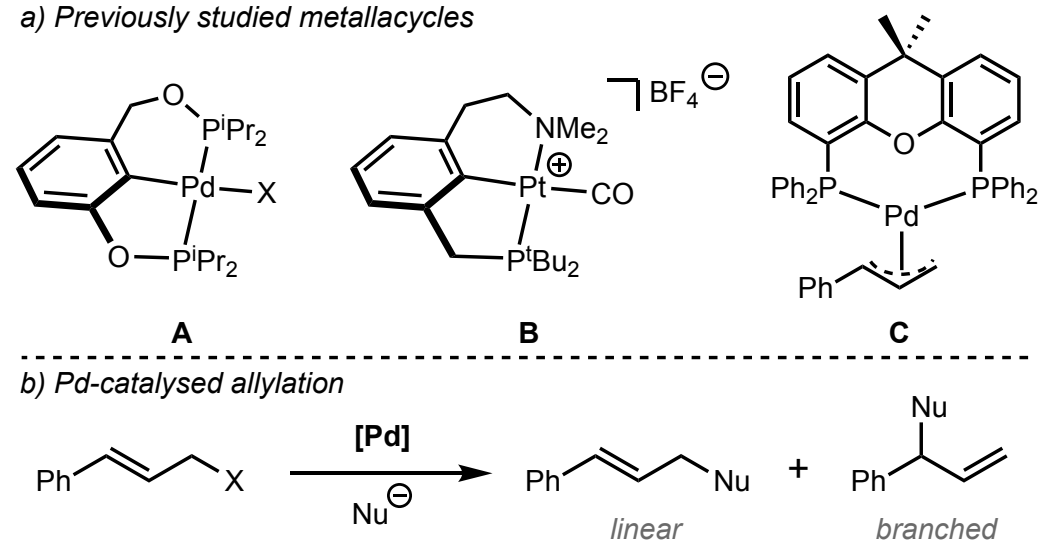

B

C

c) This work

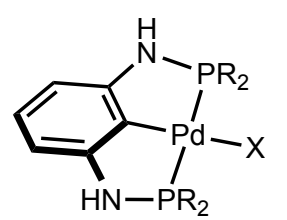

5,5-metallacycle

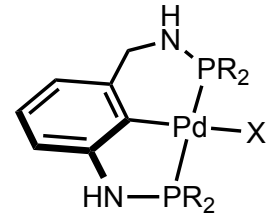

5,6-metallacycle

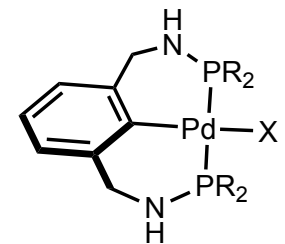

6,6-metallacycle

Reactivity?

Figure 1. a) Previously reported metallacycles A-C..$^{11,18,19}$ b) Pd-catalysed allylic substitution to give linear and branched products. c) Aminophosphine PCP-Pd(II) complexes studied in this work.

Milstein et al. studied the difference in reactivity between a 'normal' 5,5-metallacyclic Pt(II) complex and the 'long-arm' variant (5,6-metallacyclic Pt(II) complex, B). ${ }^{18,20}$ The hemilability of the 6-membered amine metallacycle was implicated in the quantitative formation of a trinuclear Pt cluster when the $P C N$-Pt(II) pincer complex was reduced with $\mathrm{H}_{2}$ at $65^{\circ} \mathrm{C}$. Under the same conditions, the 'conventional' 5,5metallacycle was found to be completely inert.

Transition metal-catalysed allylic substitution reactions (Figure 1b) are useful organic transformations that have been applied in the synthesis of pharmaceuticals and natural products. ${ }^{21-23}$ van Leeuwen and Kamer reported the effect of diphosphine bite angle in Pd-catalysed allylic alkylation. ${ }^{19,24-28}$ As the ligand bite angle increased, a decrease in catalytic activity was observed, coupled with a stronger preference for the linear alkylation. ${ }^{19}$ For the largest bite angle Pd-diphosphine complex (C) employed, (Xantphos, bite angle $=110^{\circ}$ ), exclusive formation of the linear product was observed, albeit at a slow rate. The high selectivity was attributed to a steric effect of the diphosphine embracing the allyl fragment, and thereby inhibiting formation of the branched regioisomer. High linear selectivity at high catalyst activity was achieved with the moderately wide bite angle ligand DPEPhos $\left(102.7^{\circ}\right)$.

A structure-activity relationship for symmetric 5,5-metallacyclic and non-symmetric 5,6-metallacyclic $\mathrm{Pd}(\mathrm{II})$ pincer complexes was reported by Eberhard et al. ${ }^{11,16}$ These pincer complexes were applied as 
catalysts for the alkylation of cinnamyl acetate with sodium dimethylmalonate and the regioselectivity was found to be sensitive to the ligand structure (Scheme 1). The 5,6-metallacycles were found to be more active catalysts than the 5,5-metallacycles while maintaining high linear to branched product ratios (up to $95 \%$ linear selectivity). It was reported that the synthesis of the analogous $\mathrm{Pd}(\mathrm{II})$ pincer complexes with two 6membered metallacycles was not successful although it was predicted that 6,6-metallacycles may show even higher catalytic activity in allylic alkylation.

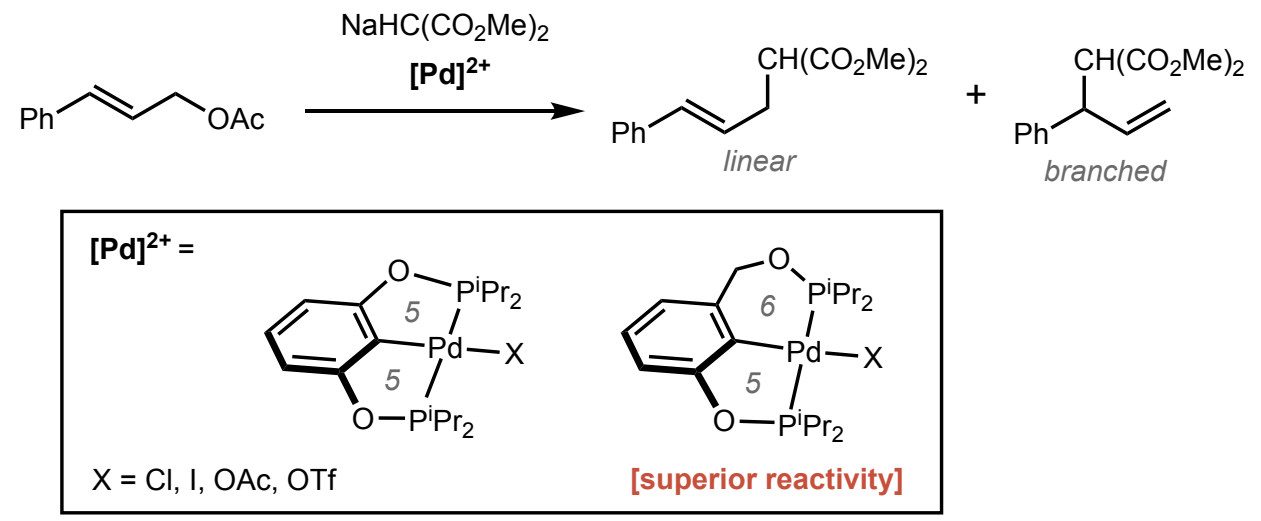

Scheme 1. Pd-pincer catalysed alkylation of cinnamyl acetate with sodium dimethylmalonate, Eberhard et al. ${ }^{11,16}$

Herein, we report a series of symmetric and non-symmetric aminophosphine $P C P$-pincer complexes and an evaluation of their performance in catalytic allylation of dimethylmalonate (Figure 1c). To investigate the effect of metallacycle ring size on the Pd coordination chemistry and catalytic activity of organometallic pincer complexes, we have studied structure-activity relationships for aminophosphine Pd-pincer complexes as catalysts for the allylation of dimethylmalonate, and compared our novel derivatives to the current state-of-the-art catalysts.

\section{Results and Discussion}

\section{Synthesis of aminophosphine ligands}

The aminodiphosphine ligands L1-L9 were made by the routes shown in Scheme 2. They have high stability to air and moisture and were readily prepared from commercially available amine precursors. For the previously reported ligands (L1-L3), the spectroscopic data matched the literature data. ${ }^{29}$ Deprotonation of the appropriate diamine precursor using either 4-dimethylaminopyridine (DMAP) or ${ }^{\mathrm{n}} \mathrm{BuLi}$, followed by reaction with the corresponding chlorophosphine gave the novel ligands L4-L9 in $75-90 \%$ yield. Full experimental and characterisation details are given in the ESI. 

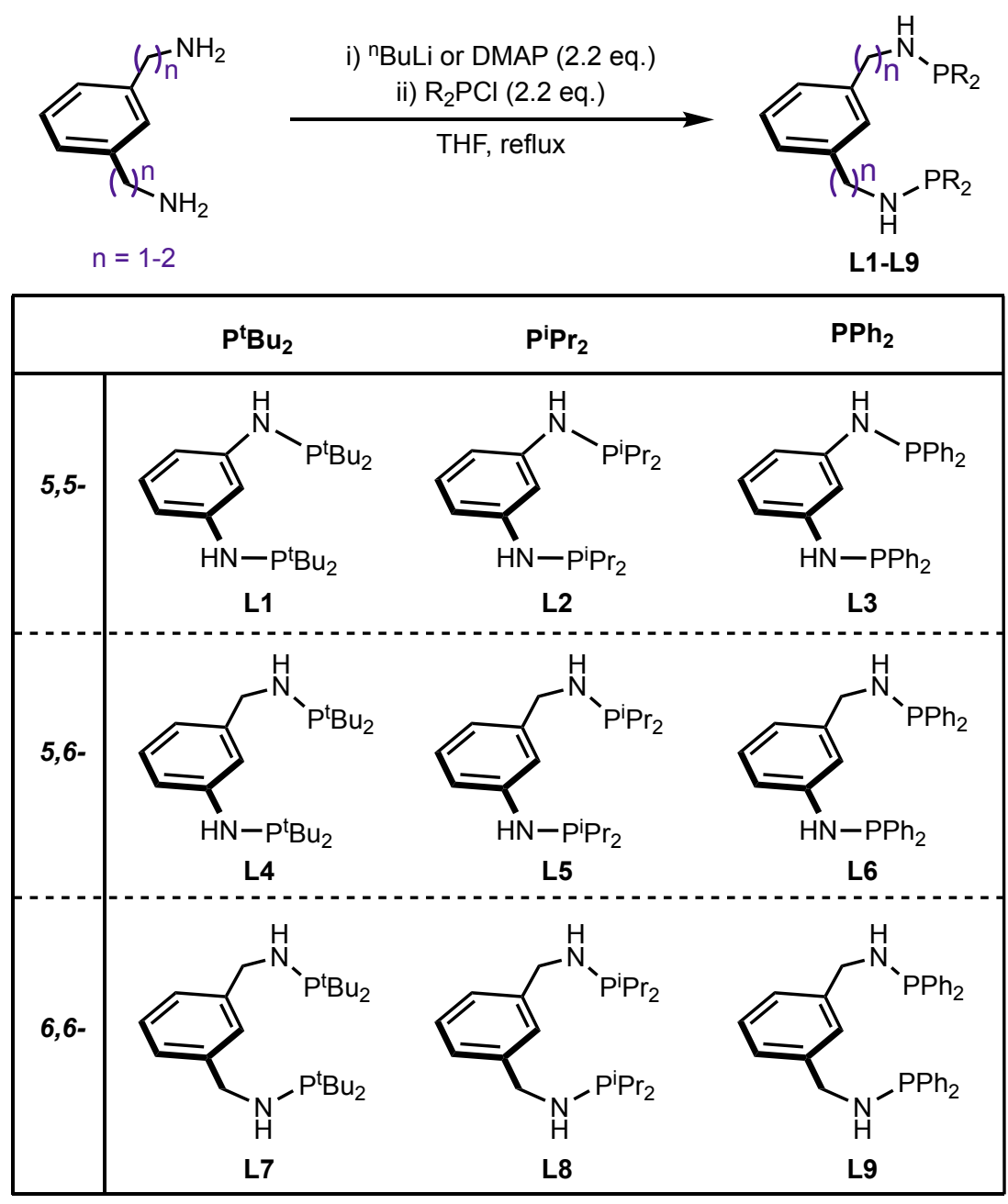

Scheme 2. Synthesis of aminophosphine ligands L1-L9.

The two ${ }^{31} \mathrm{P}$ NMR signals for the unsymmetrical diphos ligand $\mathbf{L 4}$ are singlets $\left(\delta_{\mathrm{P}}=81.6\right.$ and $59.3 \mathrm{ppm}$, ${ }^{7} J_{\mathrm{PP}}$ was not detected) with $\delta_{\mathrm{P}}$ values similar to the corresponding values in the related symmetrical diphos ligands $\mathbf{L 1}\left(\delta_{\mathrm{P}}=58.2 \mathrm{ppm}\right)$, and $\mathbf{L} 7\left(\delta_{\mathrm{P}}=81.6 \mathrm{ppm}\right)$.

\section{Palladium coordination chemistry}

In view of its relevance to the catalysis (see below), a study of the Pd coordination chemistry of L1-L9 has been carried out. The symmetrical pincer $\mathbf{L 1}$ was reacted in a 1:1 molar ratio with $\left[\mathrm{PdCl}_{2}(\mathrm{cod})\right]$ in toluene under reflux for $18 \mathrm{~h}$. Analysis of the in situ ${ }^{31} \mathrm{P}\left\{{ }^{1} \mathrm{H}\right\}$ NMR spectrum showed a singlet resonance $\left(\delta_{\mathrm{P}}=119.5\right.$ ppm) assigned to the pincer complex 1a. The formation of the 5,5-metallacycle is associated with a large, positive coordination chemical shift $\left(\Delta \delta_{\mathrm{P}}=+61.3 \mathrm{ppm}\right)$. As with the free ligand, the symmetry of the molecule means there are only two aryl-C-H resonances in the ${ }^{1} \mathrm{H}$ NMR spectrum. Formation of the desired $\mathrm{Pd}-\mathrm{Cl}$ complexes (1a-3a) derived from L1-L3 was confirmed by comparison with the previously reported spectroscopic data. ${ }^{30}$ 
The coordination of the 5,6- $\mathrm{P}^{t} \mathrm{Bu}_{2}$ ligand $\mathbf{L 4}$ to $\mathrm{Pd}(\mathrm{II})$ is surprisingly easy compared to $\mathbf{L 1}$. Immediately upon addition of a dichloromethane solution of $\mathbf{L} 4$ to $\left[\mathrm{PdCl}_{2}(\mathrm{NCPh})_{2}\right]$, the in situ ${ }^{31} \mathrm{P}\left\{{ }^{1} \mathrm{H}\right\} \mathrm{NMR}$ spectrum showed an $\mathrm{AB}$ pattern with a large ${ }^{2} J_{\mathrm{PP}}$ of $406 \mathrm{~Hz}$ consistent with 4a (Scheme 3) having a trans geometry. ${ }^{11,16}$ The different chelate ring sizes influence the coordination chemical shifts which, for the 6membered metallacycle is small $\left(\Delta \delta_{\mathrm{P}}=+8.2 \mathrm{ppm}\right)$, and for the 5 -membered metallacycle is large $\left(\Delta \delta_{\mathrm{P}}=\right.$ $+63.0 \mathrm{ppm})$; the latter $\Delta \delta_{\mathrm{P}}$ is similar to the value for the symmetrical complex $\mathbf{1 a}\left(\Delta \delta_{\mathrm{P}}=+61.3 \mathrm{ppm}\right) .^{31,32}$

a)

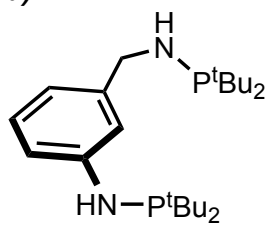

L4

b)

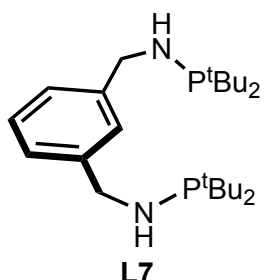

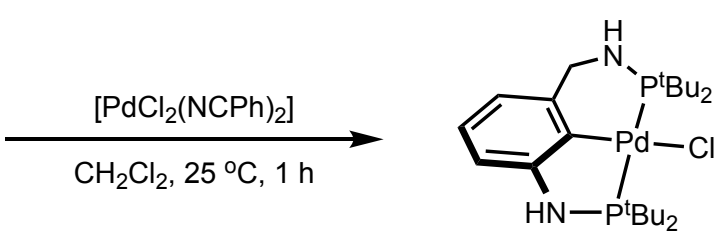

4a

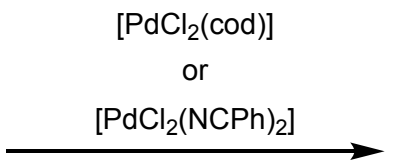

Toluene, $100^{\circ} \mathrm{C}, 18 \mathrm{~h}$

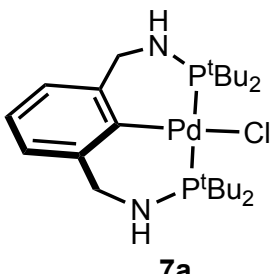

Scheme 3. Formation of 5,6- $\mathrm{Pd}-\mathrm{Cl}$ complex $4 \mathbf{a}$ and 6,6- $\mathrm{Pd}-\mathrm{Cl}$ complex 7a.

Clearly, there is a difference in kinetics of the cyclopalladation of $\mathbf{L} 1$ and $\mathbf{L 4}$, with 5,5-metallacycle formation requiring elevated temperatures and extended reaction time while the 5,6-metallacycle formation occurred rapidly at room temperature. It was anticipated that the formation of a symmetric 6,6-metallacycle would be rapid, but this was found not to be the case. When $\mathbf{L} 7$ and $\left[\mathrm{PdCl}_{2}(\mathrm{NCPh})_{2}\right]$ were mixed in $\mathrm{CH}_{2} \mathrm{Cl}_{2}$ (or toluene) two broad signals $\left(\delta_{\mathrm{P}}=+78\right.$ and $+79 \mathrm{ppm}$ ) were observed in the in situ ${ }^{31} \mathrm{P}\left\{{ }^{1} \mathrm{H}\right\}$ NMR spectra. The isolated product had limited solubility and was assigned to a diphos-bridged polymeric material, reminiscent of previously reported work on Pd bis(phosphite) $P C P$-pincer complexes. ${ }^{33}$ It was found that the metallacycle $\mathbf{7 a}$ was formed when the reaction of $\mathbf{L} 7$ and $\left[\mathrm{PdCl}_{2}(\operatorname{cod})\right]$ was carried out in toluene under reflux (Scheme 3) for $4 \mathrm{~h}$. The ${ }^{31} \mathrm{P}\left\{{ }^{1} \mathrm{H}\right\}$ NMR spectrum of the product formed under these more forcing conditions showed a singlet resonance at $\delta_{\mathrm{P}}=+89 \mathrm{ppm}$ and the HR-ESI-MS showed a molecular ion peak at $m / z 563.1713$ corresponding to $[\mathrm{M}-\mathrm{H}]^{\circ+}$ for $7 \mathbf{a}$ (calc. $m / z 563.1713$ ).

Difficulties were encountered when we attempted to form non-symmetric 5,6- and symmetric 6,6-Pd-Cl metallacycles using ligands with less bulky phosphorus substituents than $\mathrm{P}^{\mathrm{t}} \mathrm{Bu}_{2}$ (e.g. $\mathrm{P}^{\mathrm{i}} \mathrm{Pr}_{2}$ and $\mathrm{PPh}_{2}$ ). In the attempted synthesis of complexes derived from $\mathrm{P}^{\mathrm{i}} \mathrm{Pr}_{2}$ ligands $\mathbf{L 5}-\mathbf{L 8}$ and $\mathrm{PPh}_{2}$ ligands $\mathbf{L 6}$-L9, mixtures containing very insoluble precipitates were obtained (See ESI for details). ${ }^{34}$ The in situ ${ }^{31} \mathrm{P}\left\{{ }^{1} \mathrm{H}\right\} \mathrm{NMR}$ 
spectra of the mixtures from the attempted synthesis of non-symmetric metallacycles did display the expected $\mathrm{AB}$ pattern along with unknown impurities (Figure S2). In these cases, the isolated material was highly insoluble coordination polymer as previously documented for related diphos ligands. ${ }^{35}$

To investigate the coordination chemistry further, $\mathrm{Pd}(\mathrm{II})$ trifluoroacetate, $\left[\mathrm{Pd}(\mathrm{TFA})_{2}\right]$ was used and found to be a suitable precursor to soluble, monomeric Pd-TFA pincer complexes with 5- or 6-membered metallacycles (Scheme 4). These cyclometallations occur rapidly under mild conditions $\left(25^{\circ} \mathrm{C}, 20 \mathrm{~min}\right)$, rather than the harsh conditions required to form some $\mathrm{Pd}-\mathrm{Cl}$ complexes $\left(110^{\circ} \mathrm{C}, 6 \mathrm{~h}\right)$. This is a consistent with the cyclometallation being an electrophilic aromatic substitution process; the rate acceleration when using $\operatorname{Pd}(\mathrm{TFA})_{2}$ has been previously observed in other cyclopalladations. ${ }^{34,36}$

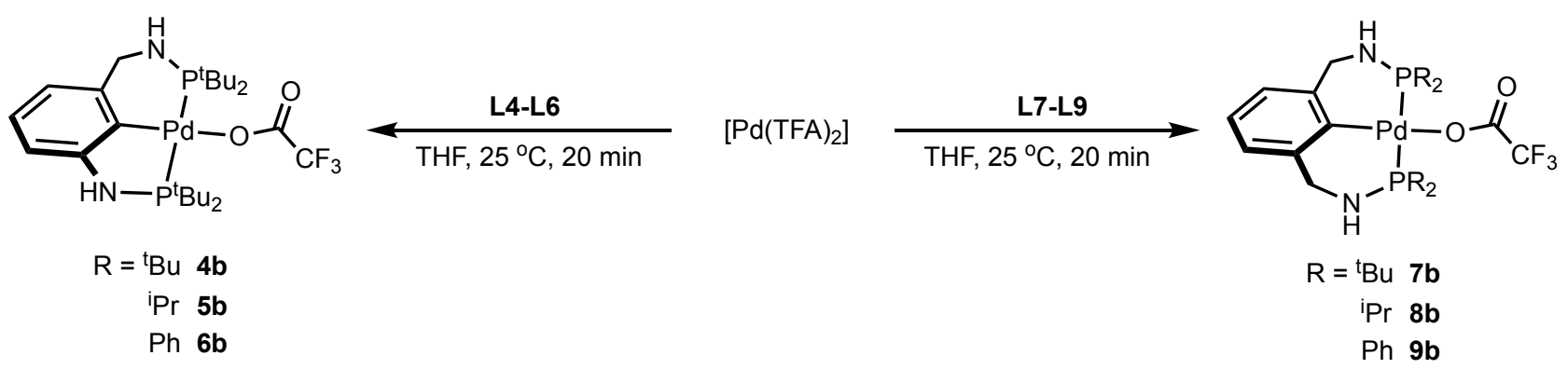

Scheme 4. Formation of Pd-TFA complexes $\mathbf{4 b - 9 b}$.

The formation of soluble 6,6-metallacyclic Pd-TFA complexes was also possible using the corresponding 6,6-ligand and $\left[\mathrm{Pd}(\mathrm{TFA})_{2}\right]$ at room temperature (Scheme 4). For the $\mathrm{P}^{\mathrm{t}} \mathrm{Bu}_{2}$ substituted ligand $\mathbf{L} 7$ this corresponded to a small downfield coordination chemical shift $\left(\Delta \delta_{\mathrm{P}}=+11 \mathrm{ppm}\right)$, thus clarifying the previously ambiguous result in the formation of $\mathrm{Pd}-\mathrm{Cl}$ complex 7a (see Scheme 3). The weakly bound nature of the trifluoroacetate ligand was evident from HR-ESI-MS experiments (see ESI). ${ }^{37}$ The mass spectrometry data support the observation that, in the gas phase, the trifluoroacetate ligand dissociates from 5,6- and 6,6-palladacycles $\mathbf{4 b}$ and $\mathbf{7 b}$, but not from 5,5-palladacycle $\mathbf{1 b}$. It is proposed that a weakly bound ligand in this position could lead to a more active catalyst, where an incoming substrate may bind to the Pd centre following ligand dissociation in this position.

\section{Effect of ring size on the crystal structures of the pincer complexes}

Crystals of 4a and 7a suitable for X-ray diffraction were grown by evaporation of their concentrated solutions in $\mathrm{CH}_{2} \mathrm{Cl}_{2}$ and hexane respectively (see Figure 2 and Figure 3). The bond lengths fall within the typical range for similar complexes; ${ }^{38,39}$ for $\mathbf{4 a}$, the Pd1-P2 (in the 6-membered ring) is longer than Pd1P1 (2.3436(4) vs. 2.3096(4) A, see Table 1), which may indicate increased strain in the larger ring. The 6membered metallacycle is in a boat conformation and the 5-membered metallacycle in an envelope conformation. From the front-on view of $\mathbf{4 a}$ (Figure 3), the $\mathrm{P}^{t} \mathrm{Bu}_{2}$ groups are above and below the aryl-Pd- 
$\mathrm{Cl}$ plane. The complex adopts a square planar geometry with a tetrahedral distortion (sum of angles around the $\mathrm{Pd} 1$ atom, $\Sigma(\mathrm{C} 1-\mathrm{Pd} 1-\mathrm{C} 11+\mathrm{P} 1-\mathrm{Pd} 1-\mathrm{P} 2)=334.7^{\circ}$, less than the ideal $\left.360^{\circ}\right)$.
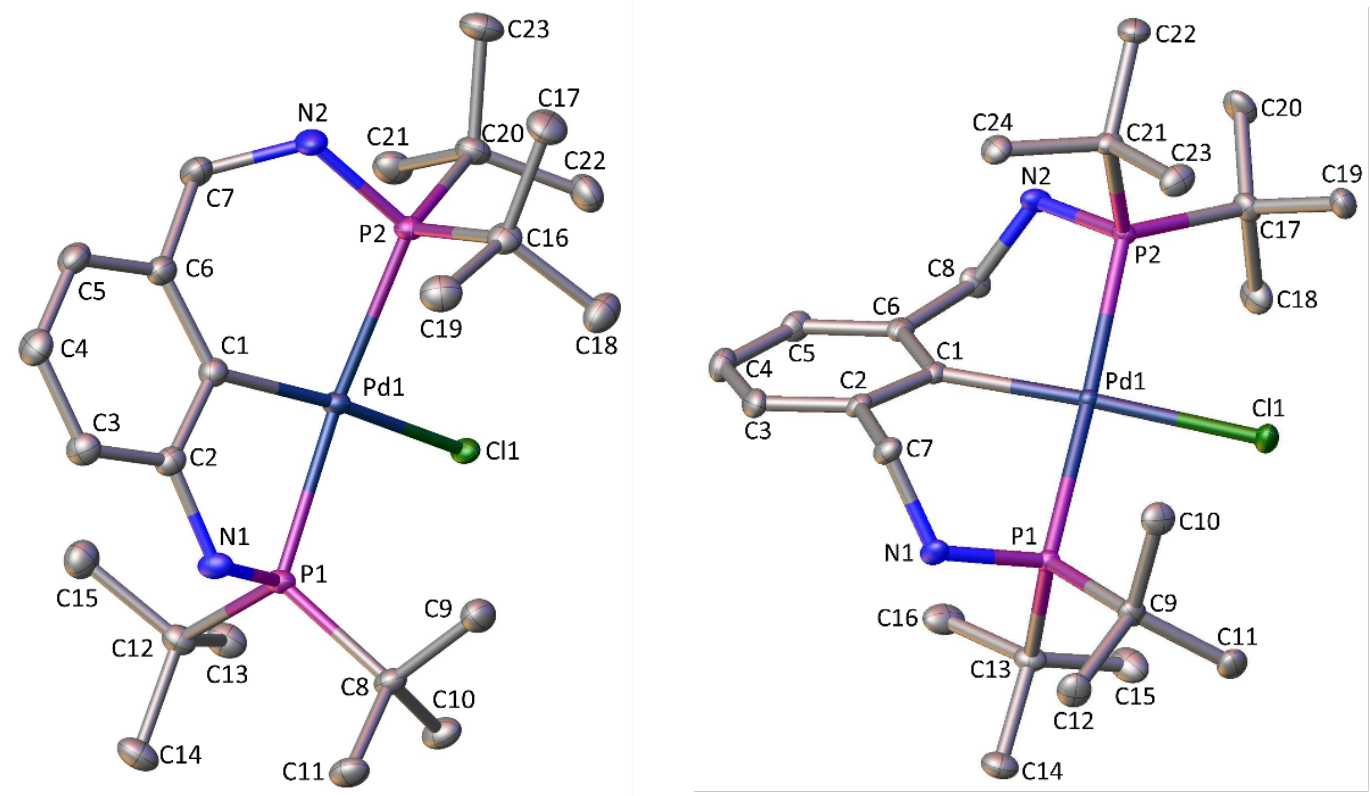

Figure 2. Single crystal X-ray crystallography structures of $\mathbf{4 a}$ (left) and 7a (right) (side view). Hydrogen atoms have been omitted for clarity. Thermal ellipsoids at $50 \%$ probability level.
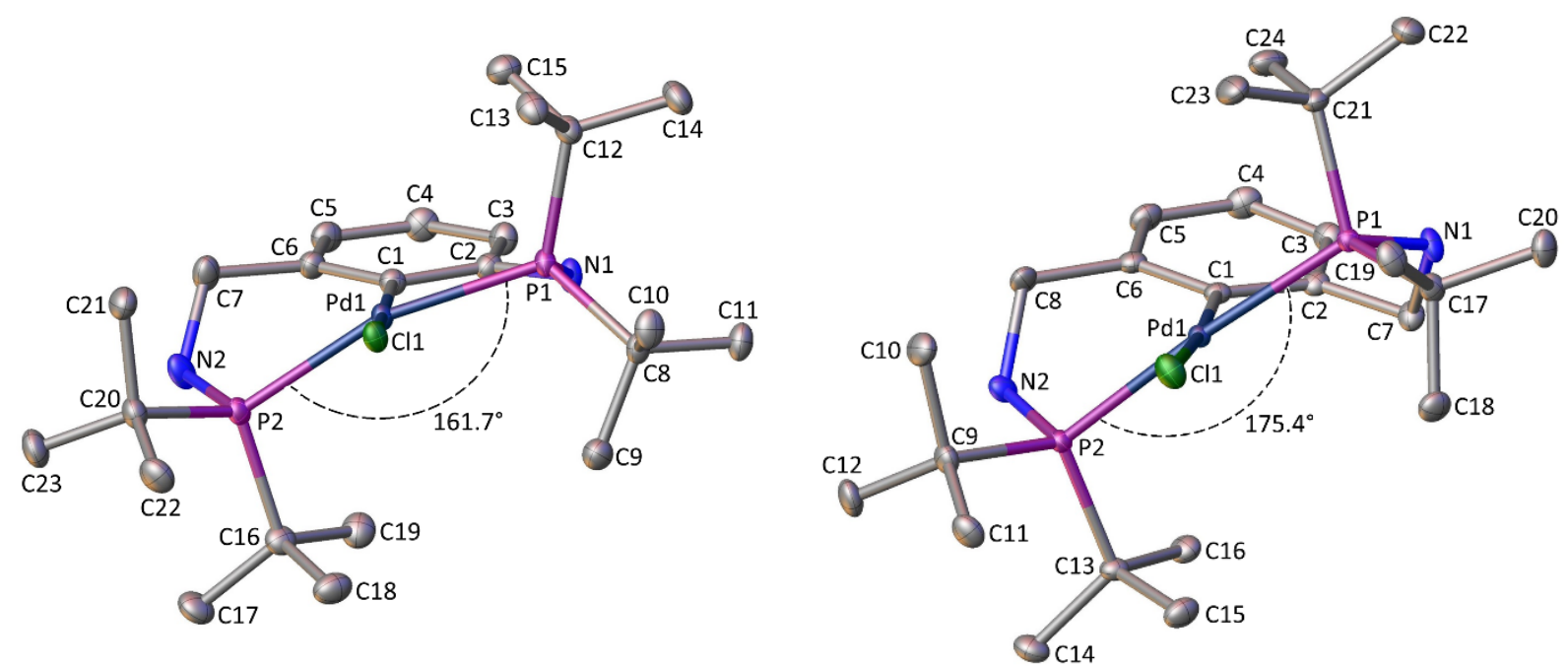

Figure 3. Single crystal X-ray crystallography structures of $\mathbf{4 a}$ (left) and 7a (right) (front view). Hydrogen atoms have been omitted for clarity. Thermal ellipsoids at $50 \%$ probability level. 
The crystal structure of 7a (Figure 3) shows the conformations of the 6-membered chelate rings are half chairs with pseudo axial and equatorial ${ }^{\mathrm{t}} \mathrm{Bu}$ groups. Due to the two methylene groups in the ligand backbone, the $\mathrm{P}^{\mathrm{t}} \mathrm{Bu}_{2}$ substituents are held above and below the aryl-Pd-Cl plane. Complex $7 \mathbf{a}$ adopts a square planar geometry with a smaller tetrahedral distortion than 4a (sum of angles, $\Sigma(\mathrm{C} 1-\mathrm{Pd} 1-\mathrm{C} 11+\mathrm{P} 1-\mathrm{Pd} 1-\mathrm{P} 2)=$ $350.3^{\circ}$ ). Moreover, owing to the additional methylene unit in the ligand backbone, the crystallographic bite angle (P1-Pd1-P2) for $7 \mathbf{a}$ is $175.4^{\circ}$ which is $\sim 14^{\circ}$ larger than for the non-symmetric 5,6-metallacycle $4 \mathbf{a}$.

The bite angle for $7 \mathbf{a}$ is greater than the 5,6- $\mathrm{P}^{\mathrm{i}} \mathrm{Pr}_{2} \mathrm{Pd}-\mathrm{Cl}$ complex $(\mathbf{A})$ reported by Eberhard $(\mathrm{P}-\mathrm{Pd}-\mathrm{P}=$ $168.3^{\circ}$, see Figure 1a), and the analogous 5,5- $\mathrm{P}^{\mathrm{i}} \mathrm{Pr}_{2} \mathrm{Pd}-\mathrm{Cl}$ complex $\left(\mathrm{P}-\mathrm{Pd}-\mathrm{P}=160.4^{\circ}\right) .{ }^{11}$

Table 1. Selected bond lengths $(\AA)$ and bond angles $\left(^{\circ}\right)$ in 5,6-metallacycle (4a) and 6,6-metallacycle (7a). For details see ESI.

\begin{tabular}{ccc}
\hline Bond & $5,6-\mathrm{Pd}-\mathrm{Cl}(\mathbf{4 a})(\AA)$ & $6,6-\mathrm{Pd}-\mathrm{Cl}(\mathbf{7 a})(\AA)$ \\
\hline Pd1-Cl1 & $2.4171(3)$ & $2.3812(5)$ \\
Pd1-P1 & $2.3096(4)$ & $2.3631(5)$ \\
Pd1-P2 & $2.3436(4)$ & $2.3382(5)$ \\
Pd1-C1 & $2.0392(14)$ & $2.0580(18)$ \\
Angle & $5,6-\mathrm{Pd}-\mathrm{Cl}(\mathbf{4 a})\left({ }^{\circ}\right)$ & $6,6-\mathrm{Pd}-\mathrm{Cl}(\mathbf{7 a})\left(^{\circ}\right)$ \\
\hline P1-Pd1-Cl1 & $94.460(12)$ & $89.437(17)$ \\
P2-Pd1-C11 & $94.674(12)$ & $92.083(18)$ \\
P1-Pd1-P2 & $161.693(14)$ & $175.400(18)$ \\
C1-Pd1-Cl1 & $172.96(4)$ & $174.86(5)$ \\
\hline
\end{tabular}

As a result of the extra methylene unit in $\mathbf{4 a}$ (or two units in $\mathbf{7 a}$ ), there is a twist allowing the $\mathrm{P}^{\mathrm{t}} \mathrm{Bu}_{2}$ groups to deviate from the aryl-Pd-Cl plane. This tetrahedral distortion, that is more pronounced in $4 \mathbf{a}$ than $7 \mathbf{a}$, results in longer Pd-P bonds compared to 5,5-palladacycles $(\mathrm{Pd}-\mathrm{P}=2.303 \AA$ in $[(\mathrm{PCP}) \mathrm{PdCl}]$; $\mathrm{PCP}=1,3$ $\left.\left({ }^{t} \mathrm{Bu}_{2} \mathrm{PCH}_{2}\right)_{2}\left(\mathrm{C}_{6} \mathrm{H}_{4}\right)\right) .{ }^{40}$

\section{NMR studies of the metallacycles}

The NMR inequivalence of the $\mathrm{P}^{t} \mathrm{Bu}_{2}$ protons in the solution ${ }^{1} \mathrm{H}$ NMR spectrum of 7a (Figure $\mathrm{S} 1$ ) implies that the ring conformation is rigid on the NMR timescale. To investigate further, a crystalline sample of 7a was dissolved in 1,1,2,2-tetrachloroethane- $d_{2}$ (TCE- $\left.d_{2}\right)$ and its ${ }^{1} \mathrm{H}$ NMR spectra were recorded at intervals between $25-100{ }^{\circ} \mathrm{C}$ (Figure 4). Although significant peak broadening of the $\mathrm{P}^{\mathrm{t}} \mathrm{Bu}_{2}$ protons is observed at higher temperature, two distinct resonances persist in solution up to $100^{\circ} \mathrm{C}$. This implies that there is a high 
degree of conformational rigidity, despite the complex having a potentially more flexible structure than the analogous 5,5-metallacycle 1a.

Initially it was reasoned that the 5,6- and 6,6-palladacycles would be more flexible than analogous 5,5metallacycles due to more degrees of freedom in the ligand backbone. However, contrary to the arguments of Eberhard et al., ${ }^{11}$ we have found by X-ray crystallography and NMR studies, that including a 6membered metallacycle introduces ring strain and imposes rigidity on the pincer rings. The longer Pd-P bonds and apparent rigidity of 6-membered palladacycles may be contributing factors in their enhanced catalytic activity compared with conventional 5,5-metallacycles (see below).

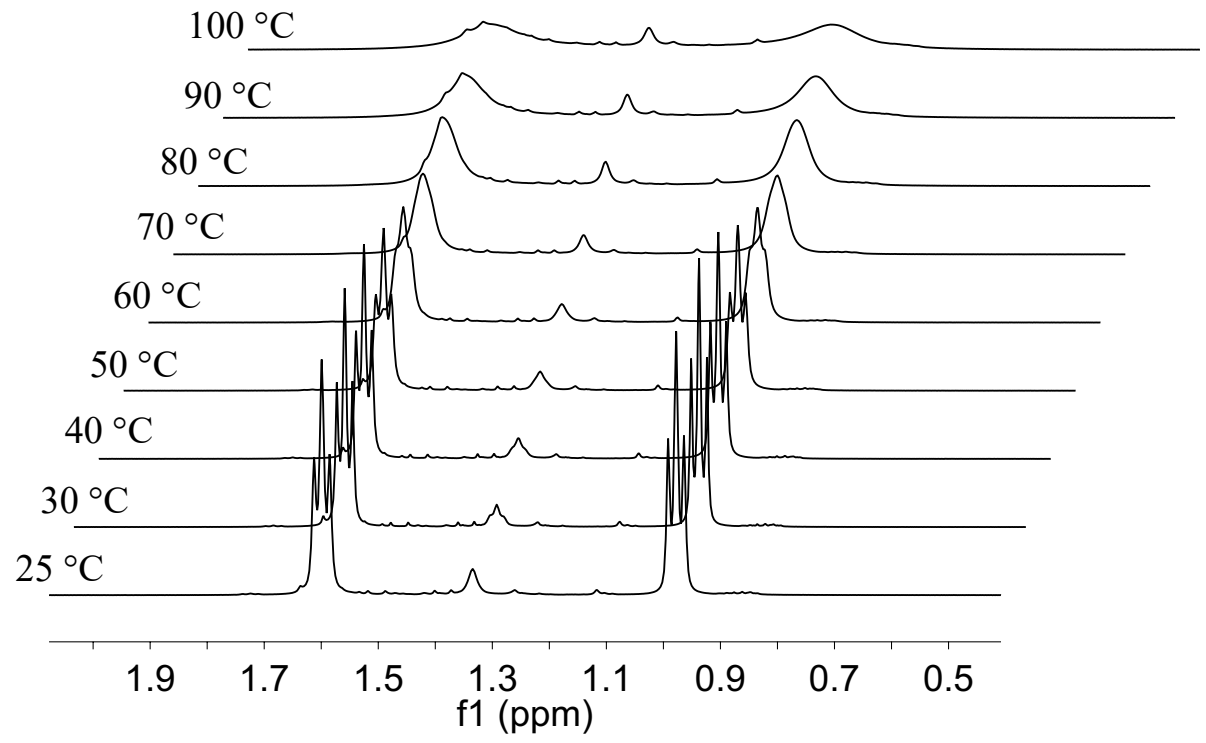

Figure 4. Selected region of the ${ }^{1} \mathrm{H}$ VT-NMR spectra of crystals of 6,6-Pd-Cl complex 7a, dissolved in TCE- $d_{2}$.

For the 5,6-metallacycles, the ${ }^{31} \mathrm{P}\left\{{ }^{1} \mathrm{H}\right\}$ NMR spectra exhibit the expected AB patterns (Figure 5) with large ${ }^{2} J_{\mathrm{PP}}$ values typical of the trans relationship $\mathrm{PdP}_{2}$ group: for $\mathbf{4 b}, \mathbf{5 b}$ and $\mathbf{6 b},{ }^{2} J_{\mathrm{PP}}=367 \mathrm{~Hz}, 388 \mathrm{~Hz}$, and 447 $\mathrm{Hz}$ respectively (Figure 5). For Pd-TFA complex $\mathbf{4 b}$, the ${ }^{2} J_{\mathrm{PP}}$ is considerably smaller than the analogous $\mathrm{Pd}-\mathrm{Cl}$ complex $4 \mathbf{a}\left({ }^{2} J_{\mathrm{PP}}=406 \mathrm{~Hz}\right)$. This trend in coupling constants for 5,6-Pd-TFA complexes $\left({ }^{2} J_{\mathrm{PP}}: \mathrm{P}^{t} \mathrm{Bu}_{2}\right.$ $<\mathrm{P}^{\mathrm{i}} \mathrm{Pr}_{2}<\mathrm{PPh}_{2}$ ) reflects the trans influence of the phosphine donor substituents (i.e., two good $\sigma$-donating $\mathrm{P}$ ligands will mutually weaken their bonds to the metal leading to a smaller ${ }^{2} J_{\mathrm{PP}}$ coupling). 


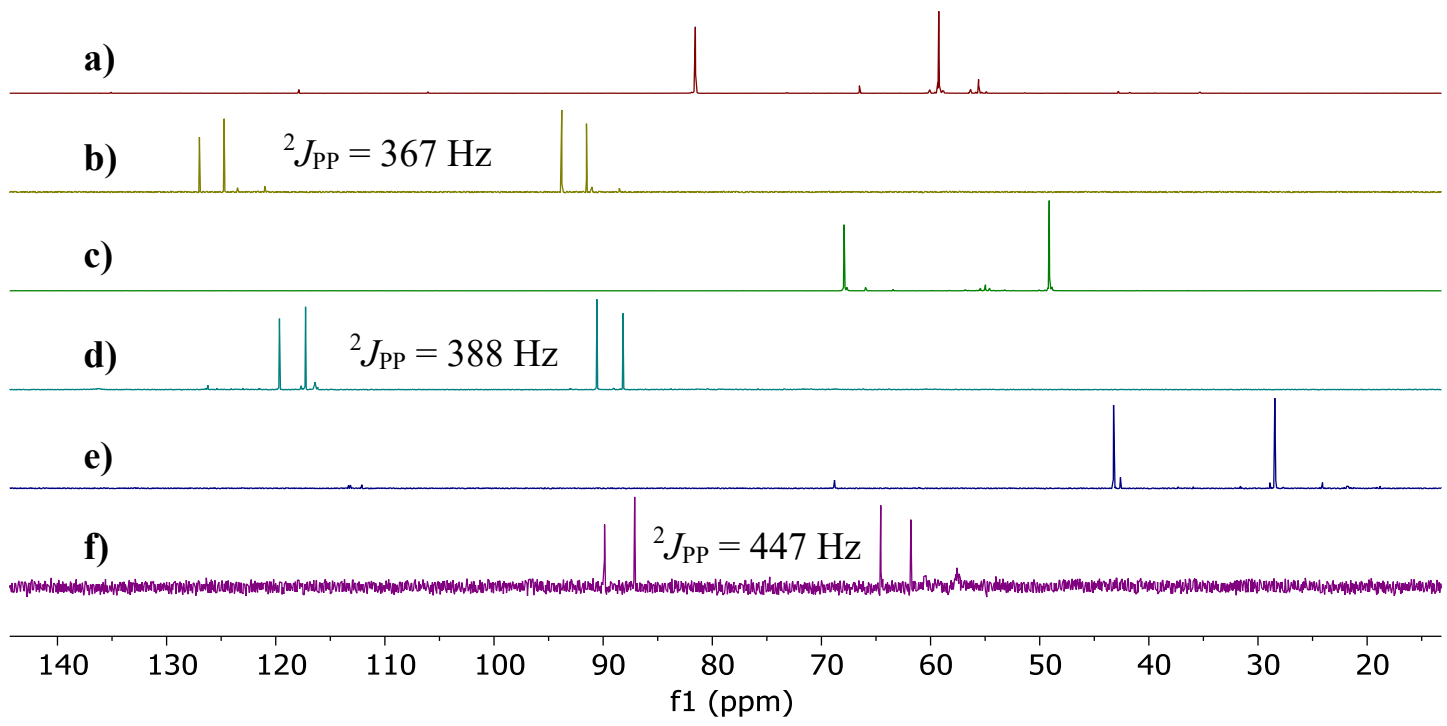

Figure 5. ${ }^{31} \mathrm{P}\left\{{ }^{1} \mathrm{H}\right\}$ NMR spectra for a) 5,6-P'Bu$(\mathbf{L} 4)$, b) 4b, c) 5,6- $\mathrm{P}^{\mathrm{i}} \operatorname{Pr}_{2}(\mathbf{L 5})$, d) 5b, e) 5,6-PPh (L6), f) $\mathbf{6 b}$. A summary of the NMR spectroscopy data for L1-L9 and associated Pd complexes is given in Table S1. 


\section{Catalytic allylation of dimethylmalonate}

\section{Catalysis under standard conditions}

The performance of the $\mathrm{Pd}-\mathrm{Cl}$ and $\mathrm{Pd}-\mathrm{TFA}$ pincer complexes of L1-L9 as catalysts for the allylation of dimethylmalonate has been investigated and the results are presented in Table 2 . Two equivalents of sodium dimethylmalonate with respect to the limiting substrate cinnamyl acetate were used. ${ }^{11}$

Table 2. Catalytic allylation of dimethylmalonate under standard conditions. ${ }^{\mathrm{a}}$

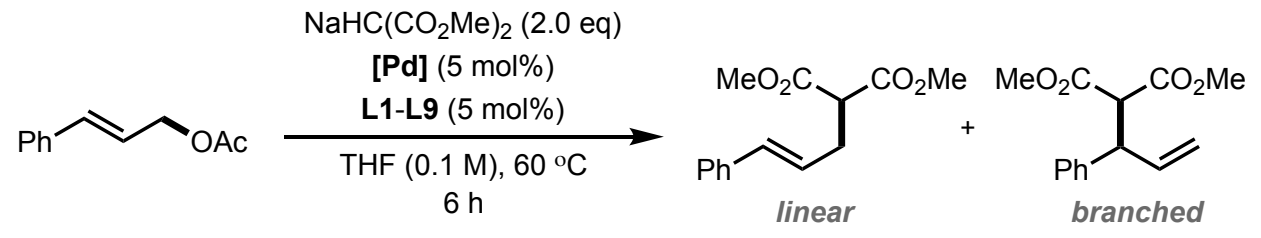

\begin{tabular}{|c|c|c|c|c|c|}
\hline Entry & Ligand & $\begin{array}{c}\% \text { Conversion }^{\mathrm{b}} \text { with } \\
{\left[\mathrm{PdCl}_{2}(\mathrm{NCPh})_{2}\right]}\end{array}$ & $\begin{array}{l}\% \text { Linear } \\
\text { selectivity }\end{array}$ & $\begin{array}{c}\% \text { Conversion }^{\mathrm{b}} \\
\text { with }\left[\operatorname{Pd}(\mathrm{TFA})_{2}\right]\end{array}$ & $\begin{array}{l}\% \text { Linear } \\
\text { selectivity }\end{array}$ \\
\hline 1 & L1 & 11 & 88 & 16 & 95 \\
\hline 2 & $\mathbf{L} 2$ & $>99$ & 75 & 52 & 84 \\
\hline 3 & $\mathbf{L 3}$ & $>99$ & 95 & $>99$ & 92 \\
\hline 4 & L4 & 58 & 91 & 70 & 93 \\
\hline 5 & L5 & $>99$ & 71 & 93 & 82 \\
\hline 6 & L6 & $>99$ & 91 & $>99$ & 93 \\
\hline 7 & L7 & $>99$ & 82 & $>99$ & 81 \\
\hline 8 & L8 & $>99$ & 92 & $>99$ & 67 \\
\hline 9 & L9 & $>99$ & 88 & $>99$ & 89 \\
\hline $10^{\mathrm{c}, \mathrm{f}}$ & L8 & $>99$ & 78 & $>99$ & 67 \\
\hline $11^{\mathrm{d}, \mathrm{f}}$ & L8 & 95 & 87 & $>99$ & 63 \\
\hline $12^{\mathrm{e}, \mathrm{f}}$ & L8 & 48 & 92 & $>99$ & 78 \\
\hline $13^{\mathrm{c}, \mathrm{g}}$ & L8 & - & - & $49^{\mathrm{h}}$ & $>99$ \\
\hline $14^{\mathrm{d}, \mathrm{g}}$ & L8 & - & - & $48^{\mathrm{h}}$ & 96 \\
\hline $15^{\mathrm{e}, \mathrm{g}}$ & L8 & - & - & $12^{\mathrm{h}}$ & $>99$ \\
\hline
\end{tabular}

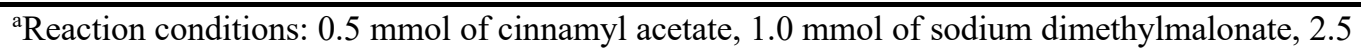
$\times 10^{-2} \mathrm{mmol}$ of [Pd], $2.5 \times 10^{-2} \mathrm{mmol}$ of ligand, in THF, $60^{\circ} \mathrm{C}, 6 \mathrm{~h}$. Results are the average of two independent experiments. ${ }^{\mathrm{b}} \mathrm{Conversion}$ and selectivity determined by GC-MS using dodecane as internal standard. ${ }^{\mathrm{c}}[\mathrm{Pd}] / \mathbf{L 8} 5 \mathrm{~mol} \%$. ${ }^{\mathrm{d}}[\mathrm{Pd}] / \mathbf{L 8} 2.5 \mathrm{~mol} \%$. ${ }^{\mathrm{e}}[\mathrm{Pd}] / \mathbf{L 8} 1.25 \mathrm{~mol} \%$. ${ }^{\mathrm{f}}$ Reaction performed at $60{ }^{\circ} \mathrm{C}$. ${ }^{g}$ Reaction performed at $25^{\circ} \mathrm{C}$. ${ }^{\text {h}}$ Reaction time $20 \mathrm{~h}$.

The progress of the reaction was monitored by GC-MS for the $\mathrm{Pd}-\mathrm{Cl}$ catalysts having $\mathrm{P}^{t} \mathrm{Bu}_{2}$ substituted ligands L1, L4 and L7 (Figure 6). From these data, the influence of metallacycle size is evident from the relative rates of reaction, with the 6,6-metallacycle reaching complete conversion in 2-3 $\mathrm{h}$, the 5,5- 
metallacycle had only reached $\sim 10 \%$ conversion after $7 \mathrm{~h}$, and the 5,6-metallcycle displayed intermediate behaviour $(60 \%$ conversion after $7 \mathrm{~h})$.

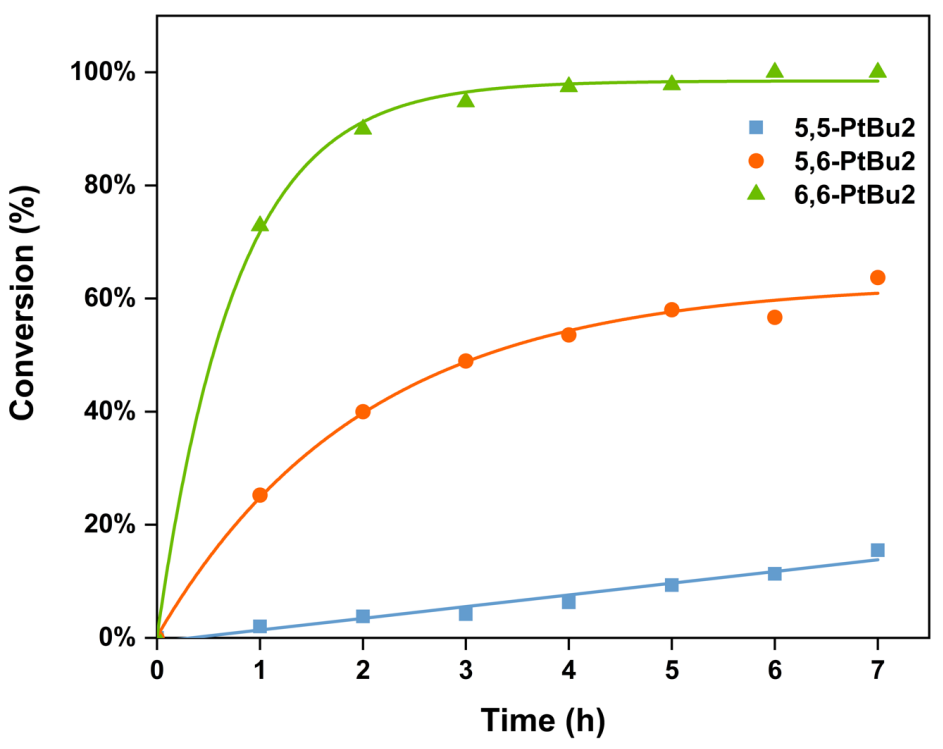

Figure 6. Conversion-time plot for the allylation of dimethylmalonate catalysed by $\mathrm{Pd}-\mathrm{Cl}$ catalysts derived from L1, L4 and L7. Conversion determined by GC-MS using dodecane as internal standard.

When the catalysis was run under the same conditions but in the absence of diphos ligand, using either $\left[\mathrm{Pd}(\mathrm{TFA})_{2}\right]$ or $\left[\mathrm{PdCl}_{2}(\mathrm{NCPh})_{2}\right]$, the conversions were $<1 \%$, in each case. No significant difference in catalytic activity was observed between runs using in situ or pre-formed pincer complex catalyst.

The following trends can be discerned from the data presented in Table 2. The catalysts derived from 5,5and 5,6- $\mathrm{P}^{\mathrm{t}} \mathrm{Bu}_{2}$ substituted aminophosphine ligands ( $\mathbf{L} \mathbf{1}$ and $\mathbf{L} 4$ respectively) (Table 2, entries 1 and 4) showed lower activity after $6 \mathrm{~h}$ than the ligands with the smaller $\mathrm{P}^{\mathrm{i}} \mathrm{Pr}_{2}$ and $\mathrm{PPh}_{2}$ substituents. Catalysts composed of 6,6-metallacycles showed superior activity to the other metallacycle sizes, with all derivatives giving $>99 \%$ conversion under the standard conditions (Table 2, entries 7-9). In general, $\mathrm{PPh}_{2}$ substituents show the highest linear selectivity (88-95\%), followed by $\mathrm{P}^{t} \mathrm{Bu}_{2}$ substituents (81-93\%), and then $\operatorname{P}^{\mathrm{i}} \operatorname{Pr}_{2}$ substituents (67-92\%).

This high activity of catalysts derived from $\mathbf{L 8}$ led us to investigate it further. The catalysis with $\mathbf{L 8}$ and $\left[\mathrm{Pd}(\mathrm{TFA})_{2}\right]$ or $\left[\mathrm{PdCl}_{2}(\mathrm{NCPh})_{2}\right]$ has been investigated as a function of the catalyst loading from $1.25-5 \mathrm{~mol} \%$ and temperature from $25-60{ }^{\circ} \mathrm{C}$ (Table 2, entries 10-15). These results demonstrated the greater activity of the $\mathrm{Pd}-\mathrm{TFA}$ catalysts than the $\mathrm{Pd}-\mathrm{Cl}$ catalysts: at $60{ }^{\circ} \mathrm{C}$, after $2 \mathrm{~h}$ and at $1.25 \mathrm{~mol} \%$ catalyst loading, full conversion was observed with Pd-TFA catalysts whilst only $48 \%$ conversion was observed with the $\mathrm{Pd}-\mathrm{Cl}$ catalyst (Table 2, entry 12). Excellent linear selectivity ( $>99 \%$ ) is maintained at $25^{\circ} \mathrm{C}$ for Pd-TFA catalysts, 
whereas the $\mathrm{Pd}-\mathrm{Cl}$ are not active at this temperature, suggesting that a more labile ligand is required for activity at low temperatures.

We performed the $\mathrm{Hg}$ drop test using $\mathbf{L 7}$ - $\mathbf{L 9}$ with either $\left[\mathrm{PdCl}_{2}(\mathrm{NCPh})_{2}\right]$ or $\left[\mathrm{Pd}(\mathrm{TFA})_{2}\right]$ to determine whether the active catalytic species was the $\mathrm{Pd}(\mathrm{II})$ pincer complexes, or if they deposited $\operatorname{Pd}(0)$ nanoparticles. ${ }^{41,42}$ For each of the ligands tested, the conversion and selectivity was not influenced by the addition of $\operatorname{Hg}(0)$ (300 eq. with respect to $\mathrm{Pd}$ ), suggesting that the active catalyst is homogeneous $\mathrm{Pd}(\mathrm{II})$ (Table S2). It has been shown that addition of elemental $\mathrm{Hg}$ is highly effective at extinguishing heterogeneous $\operatorname{Pd}(0)$ catalysts, including those generated by $P C P$-pincer complexes of $P d{ }^{43}$ Visually, the post-catalysis mixtures containing $\mathrm{Hg}$ did not appear different to runs without $\mathrm{Hg}$, suggesting homogeneous solutions.

To assess the scalability of the reaction, the best combination for catalyst activity and linear selectivity were selected. The catalysis was performed with cinnamyl acetate on a multi-gram scale $(3.5 \mathrm{~g}, 21 \mathrm{mmol})$ with $\mathbf{L 3}$ and $\left[\mathrm{PdCl}_{2}(\mathrm{NCPh})_{2}\right]$ (both at $5 \mathrm{~mol} \%$ ) at $50{ }^{\circ} \mathrm{C}$ in THF (Scheme 5). Analysis by GC-MS indicated that, at $42 \times$ scale, the outcome of the reaction was the same (full conversion, 95\% linear selectivity).

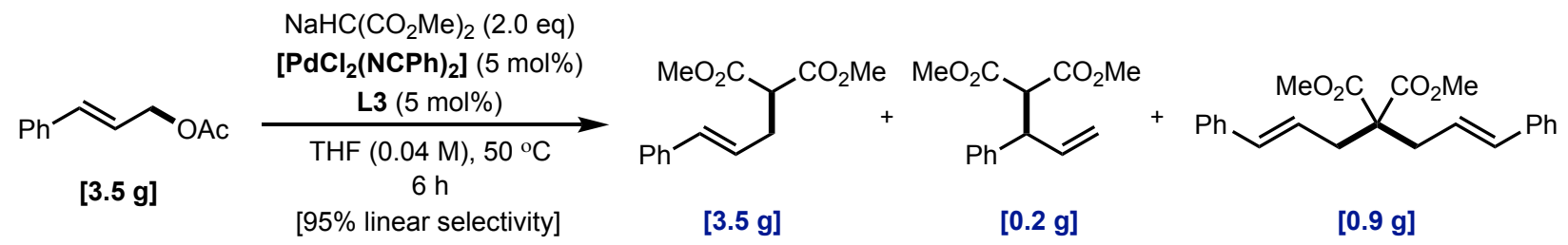

Scheme 5. Catalytic allylation of dimethylmalonate under optimal conditions.

It was also discovered that, at high conversion, another product was formed. The mole fraction of this unknown product varied (between 0.03-0.19) depending on the aminophosphine ligand (L1-L9) that was used. The product was isolated from the post-catalysis mixture and purified by column chromatography; it was identified as the product of di-allylation of dimethylmalonate (for full details see the ESI). It is still surprising that di-allylation occurs when the molar ratio of sodium dimethylmalonate to cinnamyl acetate is $2: 1$. The formation of this di-allylation product is often overlooked but was observed by Sato et al. with N-heterocyclic carbene derived Pd catalysts. ${ }^{37}$

\section{Mechanistic considerations}

The mechanism Pd(II)-pincer complex catalysed allylation is not yet fully understood and it remains a topic of debate whether $\mathrm{Pd}(0) / \mathrm{Pd}(\mathrm{II})$ and $\mathrm{Pd}(\mathrm{II}) / \mathrm{Pd}(\mathrm{IV})$ redox cycles are involved. In the study performed by Eberhard et al. utilising bis(phosphite)-Pd(II) pincer complexes, the alkylation of deuterated allylic acetate substrate resulted in products with a 1:1 ratio of $\mathrm{C}\left(\mathrm{sp}^{3}\right)$-deuteration and $\mathrm{C}\left(\mathrm{sp}^{2}\right)$-deuteration (Scheme 6), implying the reaction proceeds through a symmetrical $\left(\eta^{3}\right.$-allyl)Pd intermediate. ${ }^{11}$ In their study, it was not 
determined whether the $\mathrm{X}$ ligand (chloride, acetate, or triflate) remained bound to Pd during the catalytic cycle, and neither a $\mathrm{Pd}(0) / \mathrm{Pd}(\mathrm{II})$ nor a $\mathrm{Pd}(\mathrm{II}) / \mathrm{Pd}(\mathrm{IV})$ cycle was proposed.

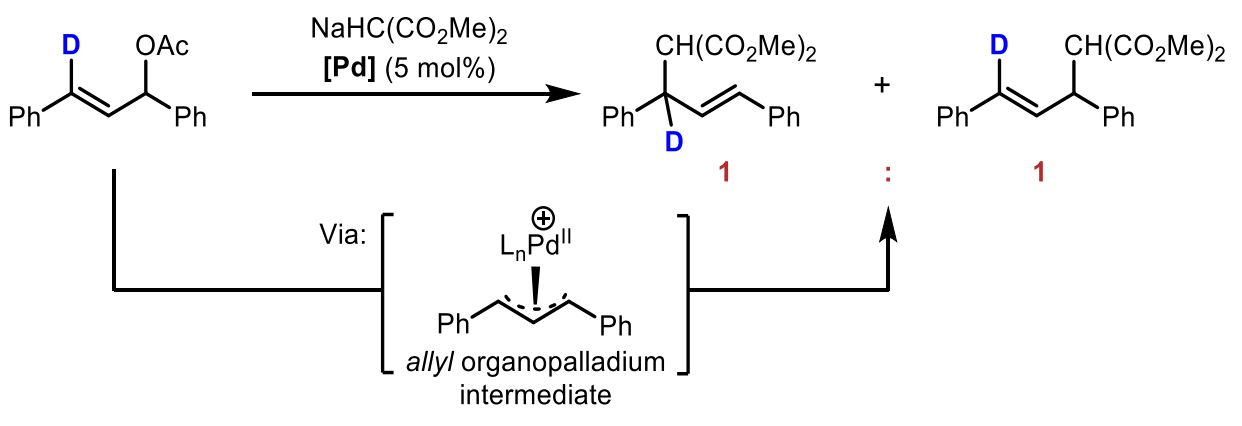

Scheme 6. Alkylation of deuterated allylic acetate, Eberhard et al. ${ }^{11}$

Furthermore, Szabó and co-workers provided evidence for bis(phosphite)-Pd(II) pincer complex catalysed allylation of aldehydes and imines via ( $\eta^{1}$-allyl)Pd intermediates. ${ }^{44}$ In 2009, the Szabó group reported that $\mathrm{Pd}(\mathrm{II})$ pincer complexes could catalyse the coupling of alkenes with diaryliodonium salts via proposed aryl$\mathrm{Pd}(\mathrm{IV})$ intermediates. ${ }^{42} \mathrm{In}$ addition, they reported allylic $\mathrm{C}-\mathrm{H}$ acetoxylation via proposed $\left(\eta^{3}\right.$-allyl)Pd(IV) intermediates. $^{45}$

Based on our findings that 5,6- and 6,6-palladacycles are rigid scaffolds and our negative $\mathrm{Hg}$ drop experiments rule out decomposition to $\operatorname{Pd}(0)$ and instead, we propose that aminophosphine $\operatorname{Pd}(\mathrm{II})$ pincer complexes catalyse allylation via $\left(\eta^{3}\right.$-allyl)Pd(IV) intermediates. The properties of the $P C P$-pincer ligands (tridentate, rigid, monoanionic chelating ligand), would facilitate stabilisation of $\operatorname{Pd}(\mathrm{IV})$ intermediates. Therefore, the following plausible mechanism is proposed (Scheme 7): (i) oxidative addition of cinnamyl acetate to give an ( $\eta^{1}$-allyl)Pd(IV) intermediate; (ii) $\eta^{3}$-allyl formation by deprotonation (loss of $\mathrm{AcOH}$ ) to give a cationic $\left(\eta^{3}\right.$-allyl)Pd(IV) intermediate; (iii) nucleophilic attack on the $\eta^{3}$-allyl predominantly at the less hindered terminus; (iv) product dissociation to complete the catalytic cycle.

Although the oxidative addition of cinnamyl acetate has not been observed with $\operatorname{Pd}(\mathrm{II})$ complexes, the formation of a $\operatorname{Pd}(\mathrm{IV})$ complex following oxidative addition with an allyl bromide was reported by Malinakova et al. ${ }^{46}$ who demonstrated that $\mathrm{Pd}(\mathrm{IV})$ oxidative addition complexes can be accessed without the use of strongly oxidising iodine(III) reagents. Through further studies, it may be possible to observe whether Pd(IV) aminophosphine pincer complexes are viable intermediates under the catalytic conditions. 


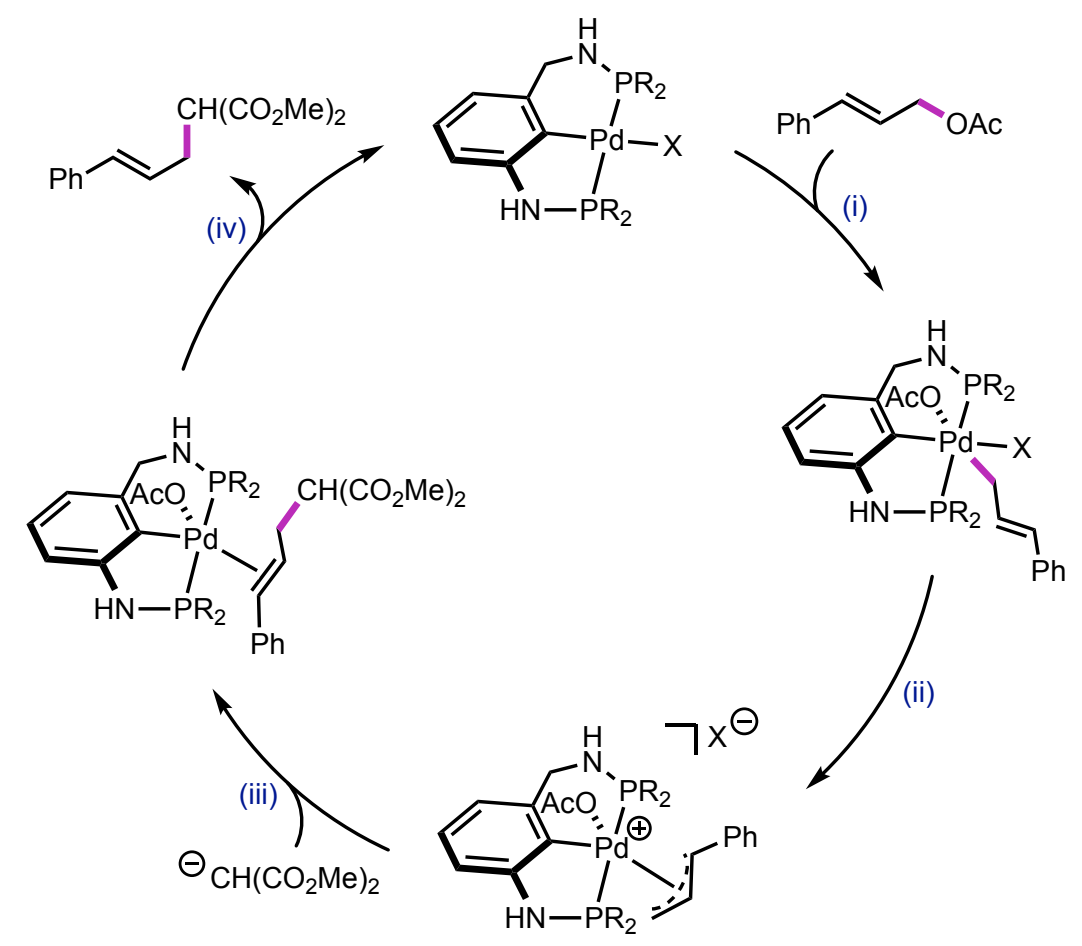

Scheme 7. Plausible catalytic cycle for allylic alkylation via $\left(\eta^{3}\right.$-allyl)Pd(IV) intermediate. $\mathrm{R}={ }^{\mathrm{t}} \mathrm{Bu},{ }^{\mathrm{i}} \mathrm{Pr}, \mathrm{Ph} . \mathrm{X}=\mathrm{Cl}$ or $\mathrm{CF}_{3} \mathrm{CO}_{2}$.

\section{Conclusions}

We have shown that aminophosphine pincer ligands (which can be readily handled in air) are prepared in high yields and purity from commercial starting materials; the synthetic route is amenable to much variation to produce ligands that could span a wide range of steric and electronic effects.

They form palladacycles with 5,5-, 5,6-, or 6,6-membered rings, whose chemistry is sensitive to the phosphine substituents and the nature of the fourth $\mathrm{X}$ ligand as shown here for $\mathrm{X}=\mathrm{Cl}$ or $\mathrm{CF}_{3} \mathrm{CO}_{2}$. The bulky $\mathrm{P}^{\mathrm{t}} \mathrm{Bu}_{2}$ ligands form very stable, soluble, monomeric $\mathrm{Pd}-\mathrm{Cl}$ complexes in any of the three metallacycle sizes. When smaller $\mathrm{P}^{i} \mathrm{Pr}_{2}$ of $\mathrm{PPh}_{2}$ substituents are present, insoluble Pd-coordination polymers are produced. On switching the anionic ligand from $\mathrm{Cl}$ to $\mathrm{CF}_{3} \mathrm{CO}_{2}$, not only are the desired monomeric pincer complexes formed, but the $\mathrm{C}-\mathrm{H}$ activation reaction is much more rapid and occurs under mild conditions. This provides access to highly active Pd(II) catalysts with a weakly bound TFA ligand and these have been applied in the catalytic allylation of dimethylmalonate.

Promising preliminary results indicate that the activity of these catalysts generally increases with increasing metallacycle size: 5,5- $<5,6-<6,6-$. In addition, the linear selectivity for the allylation product is highest for $\mathrm{PPh}_{2}$ substituted complexes which has been shown to be scalable with no decrease in activity or 
selectivity. The aminophosphine Pd-pincer complexes catalyse the allylation of dimethylmalonate with high activity and excellent linear selectivity under mild conditions.

NMR studies and the X-ray crystal structures of the pincer complexes reveal that, unexpectedly, the 6membered metallacycles are best described as more rigid and more strained than conventional 5-membered metallacycles. The strain that is apparent in the 6-membered rings may be part of the explanation for the higher catalytic activity of the pincer complexes containing 6-membered rings. Further work is in progress to explore this concept of 'strain-activation' of pincer catalysts experimentally and computationally.

\section{Conflicts of interest}

There are no conflicts to declare.

\section{Acknowledgements}

We thank the Bristol Chemical Synthesis Centre for Doctoral Training, funded by EPSRC (EP/L015366/1) and the University of Bristol, for a PhD studentship (DEW).

\section{References}

(1) Moulton, C. J.; Shaw, B. L., J. Chem. Soc., Dalton. Trans, 1976, 918, 1020-1024.

(2) Van Koten, G.; Timmer, K.; Noltes, J. G.; Spek, A. L., J. Chem. Soc. Chem. Commun., 1978, 45, $250-252$.

(3) Peris, E.; Crabtree, R. H., Chem. Soc. Rev., 2018, 47, 1959-1968.

(4) Selander, N.; Szabó, K. J., Chem. Rev., 2011, 111, 2048-2076.

(5) Younus, H. A.; Ahmad, N.; Su, W.; Verpoort, F., Coord. Chem. Rev., 2014, 276, 112-152.

(6) Valdés, H.; García-Eleno, M. A.; Canseco-Gonzalez, D.; Morales-Morales, D., ChemCatChem, 2018, 10, 3136-3172.

(7) González-Sebastián, L.; Morales-Morales, D., J. Organomet. Chem., 2019, 893, 39-51.

(8) Asay, M.; Morales-Morales, D., Dalton Trans., 2015, 44, 17432-17447.

(9) González-Sebastián, L.; Canseco-González, D.; Morales-Morales, D., Pincer Compd. Chem. Appl., 2018, 4, 467-490.

(10) Ma, L.; Woloszynek, R. A.; Chen, W.; Ren, T.; Protasiewicz, J. D., Organometallics, 2006, 25, 3301-3304. 
(11) Wang, Z.; Eberhard, M. R.; Jensen, C. M.; Matsukawa, S.; Yamamoto, Y., J. Organomet. Chem., 2003, 681, 189-195.

(12) Naghipour, A.; Sabounchei, S. J.; Morales-Morales, D.; Canseco-González, D.; Jensen, C. M., Polyhedron, 2007, 26, 1445-1448.

(13) Hung, M.-U.; Press, L. P.; Bhuvanesh, N.; Ozerov, O. V., Organometallics, 2021, 40, 1004-1013.

(14) Wagner, H. K.; Ansmann, N.; Gentner, T.; Wadepohl, H.; Ballmann, J., Organometallics, 2021, 40, 804-812.

(15) Churusova, S. G.; Aleksanyan, D. V.; Rybalkina, E. Y.; Susova, O. Y.; Brunova, V. V.; Aysin, R. R.; Nelyubina, Y. V.; Peregudov, A. S.; Gutsul, E. I.; Klemenkova, Z. S.; Kozlov, V. A., Inorg. Chem., 2017, 56, 9834-9850.

(16) Eberhard, M. R.; Matsukawa, S.; Yamamoto, Y.; Jensen, C. M., J. Organomet. Chem., 2003, 687, $185-189$.

(17) Bolliger, J. L.; Blacque, O.; Frech, C. M., Angew. Chem., Int. Ed., 2007, 46, 6514-6517.

(18) Poverenov, E.; Gandelman, M.; Shimon, L. J. W.; Rozenberg, H.; Ben-David, Y.; Milstein, D., Organometallics, 2005, 24, 1082-1090.

(19) Kranenburg, M.; Kamer, P. C. J.; Van Leeuwen, P. W. N. M., Eur. J. Inorg. Chem., 1998, $25-27$.

(20) Poverenov, E.; Gandelman, M.; Shimon, L. J. W.; Rozenberg, H.; Ben-David, Y.; Milstein, D., Chem. - A Eur. J., 2004, 10, 4673-4684.

(21) Trost, B. M.; Crawley, M. L., Chem. Rev., 2003, 103, 2921-2943.

(22) Jiang, R.; Ding, L.; Zheng, C.; You, S. L., Science, 2021, 371, 380-386.

(23) Czauderna, C. F.; Jarvis, A. G.; Heutz, F. J. L.; Cordes, D. B.; Slawin, A. M. Z.; Van Der Vlugt, J. I.; Kamer, P. C. J., Organometallics, 2015, 34, 1608-1618.

(24) Van Haaren, R. J.; Oevering, H.; Coussens, B. B.; Van Strijdonck, G. P. F.; Reek, J. N. H.; Kamer, P. C. J.; Van Leeuwen, P. W. N. M., Eur. J. Inorg. Chem., 1999, 1237-1241.

(25) Van Leeuwen, P. W. N. M.; Kamer, P. C. J.; Reek, J. N. H.; Dierkes, P., Chem. Rev., 2000, 100, 2741-2769.

(26) Van Haaren, R. J.; Druijven, C. J. M.; Van Strijdonck, G. P. F.; Oevering, H.; Reek, J. N. H.; Kamer, P. C. J.; Van Leeuwen, P. W. N. M., J. Chem. Soc., Dalton. Trans, 2000, 1549-1554.

(27) Van Haaren, R. J.; Goubitz, K.; Fraanje, J.; Van Strijdonck, G. P. F.; Oevering, H.; Coussens, B.; Reek, J. N. H.; Kamer, P. C. J.; Van Leeuwen, P. W. N. M., Inorg. Chem., 2001, 40, 3363-3372.

(28) Deerenberg, S.; Schrekker, H. S.; Van Strijdonck, G. P. F.; Kamer, P. C. J.; Van Leeuwen, P. W. N. M.; Fraanje, J.; Goubitz, K., J. Org. Chem., 2000, 65, 4810-4817.

(29) Leveson-Gower, R. B.; Webb, P. B.; Cordes, D. B.; Slawin, A. M. Z.; Smith, D. M.; Tooze, R. P.; Liu, J., Organometallics, 2018, 37, 30-39.

(30) Benito-Garagorri, D.; Bocokić, V.; Mereiter, K.; Kirchner, K., Organometallics, 2006, 25, 38173823.

(31) Lindner, E.; Fawzi, R.; Mayer, H. A.; Eichele, K.; Hiller, W., Organometallics, 1992, 11, 10331043. 
(32) Pérez, S.; López, C.; Bosque, R.; Solans, X.; Font-Bardía, M.; Roig, A.; Molins, E.; Van Leeuwen, P. W. N. M.; Van Strijdonck, G. P. F.; Freixa, Z., Organometallics, 2008, 27, 4288-4299.

(33) Baber, R. A.; Bedford, R. B.; Betham, M.; Blake, M. E.; Coles, S. J.; Haddow, M. F.; Hursthouse, M. B.; Orpen, A. G.; Pilarski, L. T.; Pringle, P. G.; Wingad, R. L., Chem. Commun., 2006, 38803882.

(34) Al-Salem, N. A.; Empsall, H. D.; Markham, R.; Shaw, B. L.; Weeks, B., J. Chem. Soc., Dalton. Trans, 1979, 1972-1982.

(35) Baber, A.; De Vries, J. G.; Orpen, A. G.; Pringle, P. G.; Von Der Luehe, K., Dalton Trans., 2006, $4821-4828$.

(36) Ike, U.; Shaw, B. L.; Thornton-Pett, M., J. Chem. Soc., Dalton. Trans, 1997, 2613-2620.

(37) Van Der Boom, M. E.; Liou, S. Y.; Ben-David, Y.; Shimon, L. J. W.; Milstein, D., J. Am. Chem. Soc., 1998, 120, 6531-6541.

(38) Ozerov, O. V.; Guo, C.; Foxman, B. M., J. Organomet. Chem., 2006, 691, 4802-4806.

(39) Benito-Garagorri, D.; Kirchner, K., Acc. Chem. Res., 2008, 41, 201-213.

(40) Kimmich, B. F. M.; Marshall, W. J.; Fagan, P. J.; Hauptman, E.; Bullock, R. M., Inorganica Chim. Acta, 2002, 330, 52-58.

(41) Foley, P.; DiCosimo, R.; Whitesides, G. M., J. Am. Chem. Soc, 1980, 102, 6713-6725.

(42) Aydin, J.; Larsson, J. M.; Selander, N.; Szabó, K. J., Org. Lett., 2009, 11, 2852-2854.

(43) Eberhard, M. R., Org. Lett., 2004, 6, 2125-2128.

(44) Solin, N.; Kjellgren, J.; Szabó, K. J., J. Am. Chem. Soc., 2004, 126, 7026-7033.

(45) Pilarski, L. T.; Selander, N.; Böse, D.; Szabó, K. J., Org. Lett., 2009, 11, 5518-5521.

(46) Guo, R.; Portscheller, J. L.; Day, V. W.; Malinakova, H. C., Organometallics, 2007, 26, 3874-3883. 